\title{
Natural hybridisation between Populus nigra L. and $P$. $x$ canadensis Moench. Hybrid offspring competes for niches along the Rhine river in the Netherlands
}

\author{
M. J. M. Smulders • R. Beringen • R. Volosyanchuk • \\ A. Vanden Broeck • J. van der Schoot • P. Arens • \\ B. Vosman
}

Received: 20 July 2007 /Revised: 18 January 2008 / Accepted: 28 January 2008 / Published online: 27 February 2008

(C) The Author(s) 2008

\begin{abstract}
Black poplar (Populus nigra L.) is a major species for European riparian forests but its abundance has decreased over the decades due to human influences. For restoration of floodplain woodlands, the remaining black poplar stands may act as source population. A potential problem is that P. nigra and Populus deltoides have contributed to many interspecific hybrids, which have been planted in large numbers. As these Populus $x$ canadensis clones have the possibility to intercross with wild $P$. nigra trees, their offspring could establish themselves along European rivers. In this study, we have sampled 44 poplar seedlings and young trees that occurred spontaneously along the Rhine river and its tributaries in the Netherlands. Along these rivers, only a few native P. nigra L. populations exist in combination with many planted cultivated $P$. $x$ canadensis trees. By comparison to reference material
\end{abstract}

Electronic supplementary material The online version of this article (doi:10.1007/s11295-008-0141-5) contains supplementary material, which is available to authorised users.

Communicated by W. Boerjan

M. J. M. Smulders $(\bowtie) \cdot$ J. van der Schoot $\cdot$ P. Arens $\cdot$ B. Vosman Plant Research International, Wageningen UR, P.O. Box 16, 6700 AA Wageningen, The Netherlands

e-mail: rene.smulders@wur.nl

R. Beringen

Stichting Floristisch Onderzoek Nederland (FLORON),

Leiden, The Netherlands

R. Volosyanchuk

Ukrainian Research Institute of Forestry and Forest Melioration,

Kharkiv, Ukraine

A. Vanden Broeck

Research Institute for Nature and Forest (INBO),

Gaverstraat 4,

9500 Geraardsbergen, Belgium from $P$. nigra, $P$. deltoides and $P . x$ canadensis, speciesspecific AFLP bands and microsatellite alleles indicated that nearly half of the sampled trees were not pure $P$. nigra but progeny of natural hybridisation that had colonised the Rhine river banks. The posterior probability method as implemented in NewHybrids using microsatellite data was the superior method in establishing the most likely parentage. The results of this study indicate that offspring of hybrid cultivated poplars compete for the same ecological niche as native black poplars.

Keywords Natural regeneration · Microsatellite - AFLP. NewHybrids $\cdot$ Posterior probability

\section{Introduction}

Black poplar (Populus nigra L.) is a characteristic species for European riparian forests. The forests have been reduced strongly in the past by human developments along the rivers and by management aiming at narrowing the path of the river (Lefèvre et al. 1998). During the last 10 years, views on river management have changed and now the aim is to give rivers more space and to restore floodplain woodlands (Hughes et al. 2001). Remaining black poplar stands may act as source populations for recolonisation in the newly created riparian ecosystems. These new populations should contain sufficient genetic diversity to allow them to adapt to changing environmental conditions and for long-term survival of the populations (Booy et al. 2000).

P. nigra also plays a central role in poplar breeding programmes and has contributed to many successful interspecific hybrids (Frison et al. 1995). The introduction of large numbers of some $P$. x canadensis clones (offspring 
of Populus deltoides $\times$ P. nigra crosses) and $P$. nigra varieties, which have the possibility to intercross with wild $P$. nigra trees, has raised concern about the genetic diversity and integrity of P. nigra in Europe (Frison et al. 1995; Heinze 1997; Lefèvre et al. 1998, 2002; Arens et al. 1998; Vanden Broeck et al. 2006). Populus $x$ canadensis trees produce seeds sired by either $P$. $x$ canadensis or $P$. nigra (Heinze and Lickl 2002). P. nigra produces seeds sired by P. $x$ canadensis if no P. nigra pollen is available (Vanden Broeck et al. 2004). A few studies have tried to quantify to what extent such hybrid offspring is actually able to establish itself in nature. They found variable percentages: no establishment in natural populations (Fossati et al. 2003), only a few hybrid trees, estimated at $0-5 \%$ (Heinze and Lickl 2002), 9.7\% (Benetka et al. 1999), $12 \%$ (Pospíšková and Šálková 2006) and 19.3\% (Ziegenhagen et al. 2008). Heinze and Lickl (2002) doubted whether the genomes of $P$. deltoides and $P$. nigra are sufficiently congruent to allow F2 and BC in all directions, but Vanden Broeck et al. (2004) found evidence for gene flow between cultivated hybrid poplars and native black poplar. Indeed, several of the 27 hybrid offspring trees identified by Ziegenhagen et al. (2008) had combinations of the $P$. deltoides DT chloroplast haplotype and/or the $P . x$ canadensis WIN3 genotype that were consistent with F2 or backcrosses.

A major problem in identifying hybrid offspring is the sensitivity of the methods used, especially if further generation hybrids such as F2 or backcrosses have to be identified. Although the morphological plant descriptor for P. nigra (Van Slycken 1996) was suitable to distinguish mature $P$. nigra from hybrids in genebank collections (Storme et al. 2002, 2004), its resolution is limited for (repeated) backcrosses between the hybrid and either parent. Identification of young seedlings is even more difficult, as features such as catkin and fruit morphology, bark structure and canopy shape are not present yet, and some leaf characters are of no use for identifying young trees. A cuneate leaf base is typical for $P$. nigra, but small leaves of seedlings and young trees of $P$. $x$ canadensis also have a more cuneate base than leaves of vigorous longshoots on older trees. Glands near the top of the petiole are characteristic for $P$. deltoides and $P$. $x$ canadensis, but these glands are mostly absent on leaves of young trees and seedlings.

Since the late 1980s, isozyme and random amplified polymorphic DNA (RAPD) markers have been successfully used for identification of clones and determination of the interrelationships among poplar species (Rajora 1989; Castiglione et al. 1993; Janssen 1997). However, isozyme markers are limited by their low level of polymorphism, and RAPD markers have problems in reproducibility (Jones et al.1997). Chloroplast markers can identify the female contribution by $P$. deltoides (e.g. Heinze 1998; Holderegger et al. 2005) but cannot detect hybridisation events of $P$. nigra females with male hybrid clones (Ziegenhagen et al. 2008).

AFLP markers are considered appropriate for hybrid detection because of the large number of loci sampled across the whole genome (Arens et al. 1998), and this method can establish species and hybrid detection using a single primer pair, producing some diagnostic (speciesspecific) bands. Hybrids often have an intermediate position between the two parents (van Raamsdonk et al. 2000), but the position may become more complicated once F2 and backcrosses occur. Microsatellites are excellent markers for clone and cultivar identification in poplars (Storme et al. 2004), and some loci contain species-specific alleles (Fossati et al. 2003). However, species-specific bands can only trace backcrosses until they are lost, so a sufficiently large number of loci with species-specific alleles must be available, otherwise the classification error rate can be high (Epifanio and Phillipp 1997).

A more sophisticated way to distinguish between hybrid $\times$ hybrid and various $P$. nigra $\times$ hybrid backcrosses is to calculate posterior probabilities of ancestry using all available allele or band frequencies. In this way, all information contained in allele frequency differences between the parental species can be used. For this, computer programmes are now available, such as NewHybrids (Anderson and Thompson 2002) and HINDEX (Buerkle 2005), but their use in poplar hybrid analysis has just started (Lexer et al. 2007; Van Loo et al. 2008).

The aim of this study was to use species-specific AFLP bands and microsatellite DNA markers to identify progeny of natural hybridisation established along the Rhine river and to determine their most likely ancestry. We used samples of seedlings and young trees recruited spontaneously along the Rhine river and its tributaries in the Netherlands, where only a few native $P$. nigra populations remain (Arens et al. 1998) in combination with many planted $P$. $x$ canadensis trees. In addition, we recorded leaf characters (colour and cilia on the leaf margins) to determine whether they can be of use for hybrid identification of young trees out in the field. For reference material, we included a series of $P . x$ canadensis and $P$. deltoides trees, as possible introgression from $P . x$ canadensis is probably of larger magnitude than that from Populus $x$ generosa or from P. nigra var. Italica.

\section{Materials and methods}

Plant material

In June 1999, 44 young poplar trees were sampled along the river Rhine and its tributaries in the Netherlands (Fig. 1) 


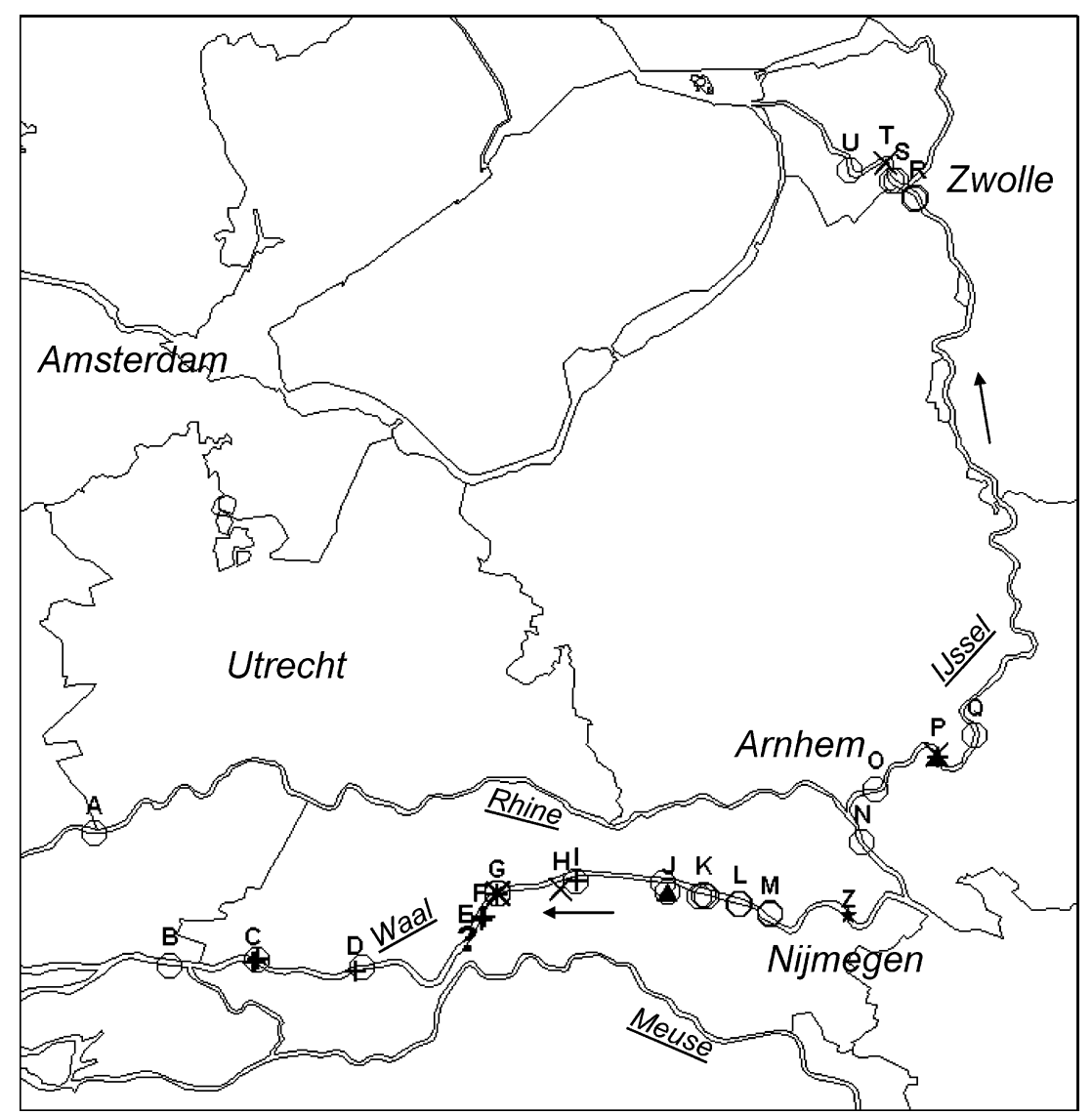

Fig. 1 Location of the sampled trees along the Rhine and its tributaries in The Netherlands. Letters refer to locations where groups of trees were sampled. The trees samples are listed in Table 2. The names of the rivers are underlined. Note that beyond the point where the IJssel side river branches off, the Rhine water level is regulated. The water level of the IJssel and the Waal $(B-Z)$ is not regulated and

during a botanical survey of river floodplains in the frame of a biological monitoring programme by the Institute for Inland Water Management and Waste Water Treatment (Odé and Beringen 2000). The trees, denoted RB, were sampled at sites with apparent natural regeneration along riverbanks, banks of clay or sandpits or between the stones of embankments. They were sampled randomly, whenever encountered during the survey and likely to have originated from seedlings. Some trees (RB23 and RB27) could have grown from twigs or branches forming roots after being washed ashore. Two somewhat older trees (RB12 and RB15) may have been planted and could have been parents of nearby sampled younger trees.

Samples were taken by cutting the ends of branches of young trees. As the sampled trees were too young for features such as catkins, fruit morphology, bark structure and canopy shape to be assessed, we recorded the two leaf characters that can be assessed: the color of the leaves and the absence-presence of minute curved hairs (cilia) on the leaf margins (Beringen 1998). Young leaves of P. nigra are green. Young leaves of $P$. deltoides and most $P . x$ the sides contain many sandy spots along the river or along pools that have an open connection to the main river, although the IJssel river sides between $\mathrm{Q}$ and $\mathrm{R}$ are mostly fortified with stones. $Z$ is the location of the P. nigra population near Gendt (Smulders et al. 2008). The Meuse was not sampled. The direction of water flow is indicated by arrows

canadensis are conspicuously red-brown or bronze coloured, although those of some P. $x$ canadensis clones (e.g. P. $x$ canadensis "Marilandica") are rather green (Houtzagers 1937). Hairs on the leaf margins are absent in P. nigra. Leaf margins of $P$. deltoides are permanently minutely pubescent, leaf margins of $P$. $x$ canadensis only when they are young (Boom 1982; Stace 1997). The latter character is not always reliable. The hairs are tiny (a magnifying glass is needed) and some P. $x$ canadensis form few short-living cilia. Trees with colored young leaves with cilia are traditionally classified as undoubtedly P. $x$ canadensis or $P$. deltoides.

For reference samples of pure $P$. nigra, young leaves were sampled from $P$. nigra trees from the European Forest Genetic Resources Programme (EUFORGEN) Core Collection (Turok et al. 1998), from P. nigra plants from Dutch populations along the Rhine, sampled in 1997 (Arens et al. 1998) and 1999 (Smulders et al. 2002, 2008), from $30 P$. deltoides Bartr. trees that have been used in hybrid poplar breeding programmes and that were available at Research Institute for Nature and Forest (INBO), Belgium and from P. $x$ canadensis Moench. (syn: Populus $x$ euramericana 
Dode (Guinier)) clones (Table S1, supplementary material Online). These $P$. $x$ canadensis clones represent commercial clones grown in The Netherlands. Their genotype is consistent with an F1 hybrid status at microsatellite locus PTR6 (Rajora and Rahman 2003), but genetically they are very likely of mixed origin: they may be $\mathrm{F} 1, \mathrm{~F} 2, \mathrm{BC} 1$ or $\mathrm{BC} 2$. When selected from open pollinations, the parentage is not really known, or it was sometimes inferred from trees that were locally present. The dataset did not include $P . x$ generosa clones. It did include one copy of P. nigra var. Italica, the Lombardy poplar, from which also introgression may occur (but not with alleles typical for another species). This is the subject of a separate study (Boerjan et al., manuscript in preparation).

Molecular analyses

The young leaves were stored at $-80^{\circ} \mathrm{C}$, lyophilised and ground with five to seven glass pearls in a Retch shaking mill directly prior to DNA extraction with the DNeasy kit (Qiagen, Helden, Germany).

AFLP analysis was performed essentially as described by Vos et al. (1995) with modifications (Arens et al. 1998; Smulders et al. 2002) using primer combination E32-M36 (5'-GACTGCGTACCAATTCAAC-3' and 5'-GAT
GAGTCCTGAGTAAACC-3'). This primer combination is sufficient to distinguish genotypes and identify clones (Storme et al. 2004; Smulders et al. 2008). Presence of a band was scored as ' 1 ', absence of a band by ' 0 '. Reproducibility was confirmed by analysing reference samples in duplicate (Arens et al. 1998)

Microsatellite analysis was performed on the reference samples and on a part of the RB trees (listed in Tables 1 and 2) using seven loci: PMGC14, WPMS09, WPMS12, WPMS14, WPMS16, WPMS18, and WPMS20. PMGC14 (5'-TTCAGAATGTGCATGATGG-3' and 5'-GTGAT GATCTCACCGTTTG-3') was developed by the Poplar Molecular Genetics Co-operative. The other loci have been described in Van der Schoot et al. (2000) and Smulders et al. (2001). Samples were analysed using a primer labelled with a fluorescent group as described in Cervera et al. (2001) on an ABI3700. Raw data were analysed using Genescan (Applied Biosystems). The assignment of singleletter codes to the alleles follows Fossati et al. (2003) and Storme et al. (2004).

Data analysis

Genetic diversity parametres were calculated with Fstat 2.9.3.2 (Goudet 1995). Microsatellite allele frequencies

Table 1 Microsatellite genotypes. Alleles in italics at loci PMGC14, WPMS09 and WPMS18 are specific for P. deltoides

\begin{tabular}{|c|c|c|c|c|c|c|c|}
\hline \multirow[t]{2}{*}{ Tree } & \multicolumn{7}{|l|}{ Locus } \\
\hline & PMGC14 & WPMS09 & WPMS12 & WPMS14 & WPMS16 & WPMS18 & WPMS20 \\
\hline RB01 & KM &.. & $\mathrm{JL}$ &.. & $\mathrm{CE}$ & GI & CG \\
\hline RB04 & EL & $\mathrm{XZ}$ & LL & $\mathrm{DM}$ & GH & CJ & $\mathrm{CF}$ \\
\hline RB05 & $\mathrm{KM}$ &.. & LL & MM & $\mathrm{CC}$ & CJ & $\mathrm{CF}$ \\
\hline RB07 &.. & $\mathrm{Bb}$ & LL & MU & $\mathrm{CI}$ & DG & DG \\
\hline RB22 & IM & QX & LL & MP &.. & GI & CG \\
\hline RB23 & $\mathrm{KK}$ &.. & $\mathrm{HH}$ & DO & $\mathrm{DE}$ & $\mathrm{H} L$ & $\mathrm{HH}$ \\
\hline RB27 & $\mathrm{KL}$ & $\mathrm{TT}$ & LL & LO & EI & GI & $\mathrm{CH}$ \\
\hline RB28 & $\mathrm{KO}$ & $G g$ & LM & $\mathrm{OO}$ & $\mathrm{HH}$ & $\mathrm{G} L$ & $\mathrm{HH}$ \\
\hline RB32 & $\mathrm{KK}$ & $G g$ & $\mathrm{KK}$ & $\mathrm{MO}$ & $\mathrm{CE}$ & $\mathrm{J} L$ & $\mathrm{FH}$ \\
\hline RB34 & $\mathrm{JK}$ & UZ & HK & $\mathrm{PP}$ & $\mathrm{EE}$ & GI & $\mathrm{DH}$ \\
\hline RB35 & EK & $G g$ & LL & $\mathrm{KO}$ & HJ & GI & $\mathrm{CH}$ \\
\hline RB36 & $\mathrm{KK}$ & UW & LL & MR & EG & $\mathrm{GH}$ & $\mathrm{EE}$ \\
\hline RB37 & IK & QW & LL & MO & EG & HI & EG \\
\hline RB38 & $P P$ & $G g$ & $\mathrm{BI}$ & FI & $\mathrm{HH}$ & $L L$ & $\mathrm{GH}$ \\
\hline RB39 & $\mathrm{K} P$ & $G g$ & LL & $\mathrm{MO}$ & HJ & $\mathrm{I} L$ & FH \\
\hline RB40 & $\mathrm{K} P$ & $\mathrm{Qg}$ & LL & $\mathrm{MO}$ & EJ & $\mathrm{I} L$ & $\mathrm{FH}$ \\
\hline RB41 & IK &.. & LL & MQ & $\mathrm{CC}$ & GI & $\mathrm{CF}$ \\
\hline RB42 & IK & QX & LL & $\mathrm{OP}$ & $\mathrm{EH}$ & DG & $\mathrm{EH}$ \\
\hline RB43 & $\mathrm{K} P$ & QQ & LL & $\mathrm{OO}$ & $\mathrm{HH}$ & $\mathrm{I} L$ & $\mathrm{FF}$ \\
\hline RB44 & $\mathrm{KM}$ & $\mathrm{XX}$ & DK & MQ & CG & DG & $\mathrm{CD}$ \\
\hline RB45 & KK & $G g$ & LL & $\mathrm{OO}$ & $\mathrm{EE}$ & $\mathrm{I} L$ & $\mathrm{FH}$ \\
\hline RB46 & EP &.. & LL & LO & HJ & $\mathrm{I} L$ & $\mathrm{FH}$ \\
\hline
\end{tabular}

Dots signify missing value 
Table 2 Most likely genotype class for the RB trees sampled. Map locations are indicated in Fig. 1
${ }^{a}$ Analysed for dominant AFLP data only, as no microsatellite data were available. Result based on AFLP data was F1, but as for all plants for which also microsatellite data were available this was invariably changed into $\mathrm{F} 2$ or $\mathrm{BC}$ to $P$. nigra, the exact hybrid classification is in fact unknown (see text)
Location on Tree Most likely genotype class the map
Probability in NewHybrids (based on either AFLP (A) or microsatellite $(\mathrm{M})$ data)

\begin{tabular}{|c|c|c|c|}
\hline A & RB01 & P. nigra & $0.99(\mathrm{M})$ \\
\hline B & RB44 & P. nigra & $0.99(\mathrm{M})$ \\
\hline $\mathrm{C}$ & RB40 & $\mathrm{BC}$ to $P$. nigra & $0.70(\mathrm{M})$ \\
\hline $\mathrm{C}$ & RB42 & P. nigra & $0.99(\mathrm{M})$ \\
\hline $\mathrm{C}$ & RB43 & $\mathrm{BC}$ to $P$. nigra & $0.84(\mathrm{M})$ \\
\hline $\mathrm{C}$ & RB45 & $\mathrm{F} 2$ & $0.99(\mathrm{M})$ \\
\hline $\mathrm{C}$ & RB46 & $\mathrm{F} 2$ & $0.57(\mathrm{M})$ \\
\hline $\mathrm{D}$ & RB39 & $\mathrm{F} 2$ & $0.99(\mathrm{M})$ \\
\hline D & RB41 & P. nigra & $0.99(\mathrm{M})$ \\
\hline $\mathrm{E}$ & RB21 & $?$ & unclear (A) \\
\hline $\mathrm{F}$ & RB28 & $\mathrm{F} 2$ & $0.97(\mathrm{M})$ \\
\hline $\mathrm{F}$ & RB30 & $\mathrm{BC}$ to $P$. nigra & $0.83(\mathrm{~A})$ \\
\hline $\mathrm{F}$ & RB31 & identical to P. $x$ canadensis 'Blanc de Poitou' (M) & \\
\hline $\mathrm{F}$ & RB32 & $\mathrm{F} 2$ & $0.99(\mathrm{M})$ \\
\hline G & RB23 & $\mathrm{BC}$ to $P$. nigra & $0.70(\mathrm{M})$ \\
\hline G & $\mathrm{RB} 24$ & Hybrid & $0.79(\mathrm{~A})^{\mathrm{a}}$ \\
\hline G & RB25 & Hybrid & $0.66(\mathrm{~A})^{\mathrm{a}}$ \\
\hline G & RB26 & P. nigra & $0.97(\mathrm{M})$ \\
\hline G & RB27 & P. nigra & $0.99(\mathrm{M})$ \\
\hline $\mathrm{H}$ & RB29 & Hybrid & $0.93(\mathrm{~A})^{\mathrm{a}}$ \\
\hline I & RB20 & $\mathrm{BC}$ to $P$. Nigra & $0.80(\mathrm{~A})$ \\
\hline I & $\mathrm{RB} 22$ & P. nigra & $1.00(\mathrm{M})$ \\
\hline $\mathrm{J}$ & RB06 & P. nigra & $0.95(\mathrm{~A})$ \\
\hline $\mathrm{J}$ & RB09 & P. nigra & 0.95 (A) \\
\hline $\mathrm{J}$ & RB11 & P. deltoides & 0.95 (A) \\
\hline K & RB02 & P. nigra & 0.95 (A) \\
\hline K & RB03 & P. nigra & $0.82(\mathrm{M})$ \\
\hline K & RB07 & P. nigra & $1.00(\mathrm{M})$ \\
\hline $\mathrm{L}$ & RB04 & P. nigra & $0.99(\mathrm{M})$ \\
\hline $\mathrm{L}$ & RB17 & P. nigra & 0.95 (A) \\
\hline M & RB05 & P. nigra & $0.99(\mathrm{M})$ \\
\hline M & RB08 & P. nigra & $0.95(\mathrm{~A})$ \\
\hline $\mathrm{N}$ & RB36 & P. nigra & $0.99(\mathrm{M})$ \\
\hline $\mathrm{O}$ & RB34 & P. nigra & 0.99 (M) \\
\hline $\mathrm{P}$ & RB33 & Hybrid & $0.99(\mathrm{~A})^{\mathrm{a}}$ \\
\hline $\mathrm{P}$ & RB35 & $\mathrm{F} 2$ & $1.00(\mathrm{M})$ \\
\hline $\mathrm{P}$ & RB38 & P. deltoides & $1.00(\mathrm{M})$ \\
\hline Q & RB37 & P. nigra & $1.00(\mathrm{M})$ \\
\hline $\mathrm{R}$ & RB15 & P. nigra & 0.95 (A) \\
\hline $\mathrm{R}$ & RB16 & P. nigra & 0.93 (A) \\
\hline S & RB12 & P. nigra & 0.95 (A) \\
\hline S & RB18 & P. nigra & 0.95 (A) \\
\hline $\mathrm{T}$ & RB14 & Hybrid & $0.79(\mathrm{~A})^{\mathrm{a}}$ \\
\hline $\mathrm{U}$ & RB19 & P. nigra & $0.95(\mathrm{~A})$ \\
\hline
\end{tabular}

were calculated with Popgene version 1.31 (http://www. ualberta.ca/ fyeh/info.htm), which was also used to calculate the genetic distances between individual samples. The Unweighted Pair Group Method for Arithmetic Averages (UPGMA) dendrogramme of AFLP data was made in NTSYS (http://www.exetersoftware.com/) using a genetic distance matrix based on the Nei 1972 genetic distance.
Hybrid and backcross genotype posterior probabilities were estimated using NewHybrids 1.0 (Anderson and Thompson 2002) for microsatellite as well as AFLP data. NewHybrids calculates the posterior probability that sampled individuals fall into each of a set of hybrid categories (Parent 1, Parent 2, F1, F2, BC to Parent 1, BC to Parent 2, thus covering parents and two generations of offspring). 
The probabilities add up to 1 ; therefore, if a given genotype has probability 0.8 for one category, the probability of the other five classes together is only 0.2. AFLP data can be used as input in Newhybrids 1.0, but the programme assumes all data to be homozygous ( 1 becomes 11, 0 becomes 00). This probably does not influence the probabilities for F1 hybrids, but it might affect those of various backcrosses.

As Anderson and Thompson (2002) indicate, the difference between NewHybrids and other programmes using Bayesian methods is that NewHybrids assumes that the sample consists of pure individuals and recent hybrids of two species and uses an inheritance model defined in terms of genotype frequencies for the various hybrid categories. This sets the number of a priori categories; it may improve the calculations of probabilities, and it also means that the groups produced are clearly labelled in terms of genetic contributions.

\section{Results}

\section{AFLP analysis of P. nigra and hybrids}

First, we determined the power of the selected AFLP primer combination to distinguish between $P$. nigra, $P$. deltoides and their hybrids. For this, 73 P. nigra individuals from the Dutch population (Arens et al. 1998) and 30 plants of $P$. deltoides that have been used in a commercial hybrid breeding programme at INBO were analysed together with ten commercial $P$. $x$ canadensis hybrid varieties. Amongst the 51 AFLP bands scored, 48 (94\%) were polymorphic in the dataset. Only one band was fully diagnostic for $P$. nigra (i.e. present in $100 \%$ of the P. nigra plants and completely absent in $P$. deltoides), but most bands did have frequency differences. Several bands were specific for $P$. deltoides.

The genetic differentiation between the two parental species $P$. nigra and $P$. deltoides was considerable $\left(G_{\mathrm{st}}=\right.$ $0.371, \mathrm{Ht}=0.198$ and $\mathrm{Hs}=0.125)$. The differentiation between $P$. deltoides and $P$. $x$ canadensis was $G_{\mathrm{st}}=0.311$, which was very similar to the $G_{\text {st }}=0.298$ between $P$. nigra and $P . x$ canadensis. This genetic differentiation is relatively large compared to that between the two parental species. This may be due to the dominant nature of AFLP markers.

To determine in which group the trees sampled along the Rhine (denoted RB) would fit best, a UPGMA clustering was performed on the basis of the genetic distance amongst all pairs of plants (Fig. 2). In the clustering, RB31 turned out to be identical to the commercial $P . x$ canadensis clone Blanc du Poitou. As it was found at a site along the shore with many poplar and willow seedlings, where obviously no planting had taken place, this tree is most probably the result of vegetative distribution through branches that manage to root and sprout.

In the cluster analysis of AFLP data, the two parental species formed separate groups, with the $P . x$ canadensis group at an intermediate branch. Ten of the sampled RB trees clustered together with the $P . x$ canadensis trees; the remaining 34 clustered together with the $P$. nigra trees from the Gendt population. This P. nigra group, however, seemed to consist of three clusters grouped together loosely, with different numbers of RB trees: the largest cluster (labelled ' $\mathrm{N}$ ') included 48 P. nigra plus four RB trees, a second cluster (labelled ' $\mathrm{M}$ ') consisted of 20 P. nigra plus $19 \mathrm{RB}$ trees and a third cluster (denoted ' $\mathrm{R}$ ') contained three $P$. nigra trees plus $11 \mathrm{RB}$ trees. All $11 \mathrm{RB}$ trees in the latter cluster showed the one discriminating AFLP marker for $P$. nigra, as well as two AFLP bands that are very frequent in P. nigra and very rare in P. deltoides.

Application of diagnostic and informative microsatellite alleles

Allele frequencies in $P$. nigra and $P$. deltoides were determined for seven microsatellite loci on a subset of the samples (Table S2, Supplementary material Online). The average number of alleles per locus was lower in $P$. deltoides than in P. nigra. This was not unexpected because six of the seven markers were developed in P. nigra, and often polymorphic microsatellite markers are less polymorphic in related species (Smulders et al. 1997). Consistent with less repeat expansion, the average allele size in $P$. deltoides was smaller.

Two loci were monomorphic in P. deltoides: WPMS09 and WPMS18. For both loci, the P. deltoides allele (' $\mathrm{g}$ ' at WPMS09 (234 bp), 'L' at WPMS18 (220 bp)) was not found in P. nigra, so these alleles are diagnostic markers for $P$. deltoides. This corroborates the results of Fossati et al. (2003). For locus PMGC14, the most frequent $P$. deltoides allele "O" (270 bp) is very rare in P. nigra; the second to one most frequent $P$. deltoides allele "P" (268 bp) is unique to $P$. deltoides. We classify these alleles as informative, as they contain information on the likelihood of the sample belonging to a certain species or hybrid. Alleles specific for $P$. deltoides were also present at loci WPMS12, WPMS16 and WPMS20, but the frequencies of these informative alleles were too low to be useful. Locus WPMS14 has many common alleles in both species.

Using the diagnostic and informative alleles, we made inferences on the genetic background of the trees in the study. The alleles found in four out of six commercial $P . x$ canadensis clones (Table S2, Supplementary Material Online, Pxc column) were consistent with an F1 hybrid because the alleles from both parental species were present. The other two had a different genotype. P. $x$ canadensis 


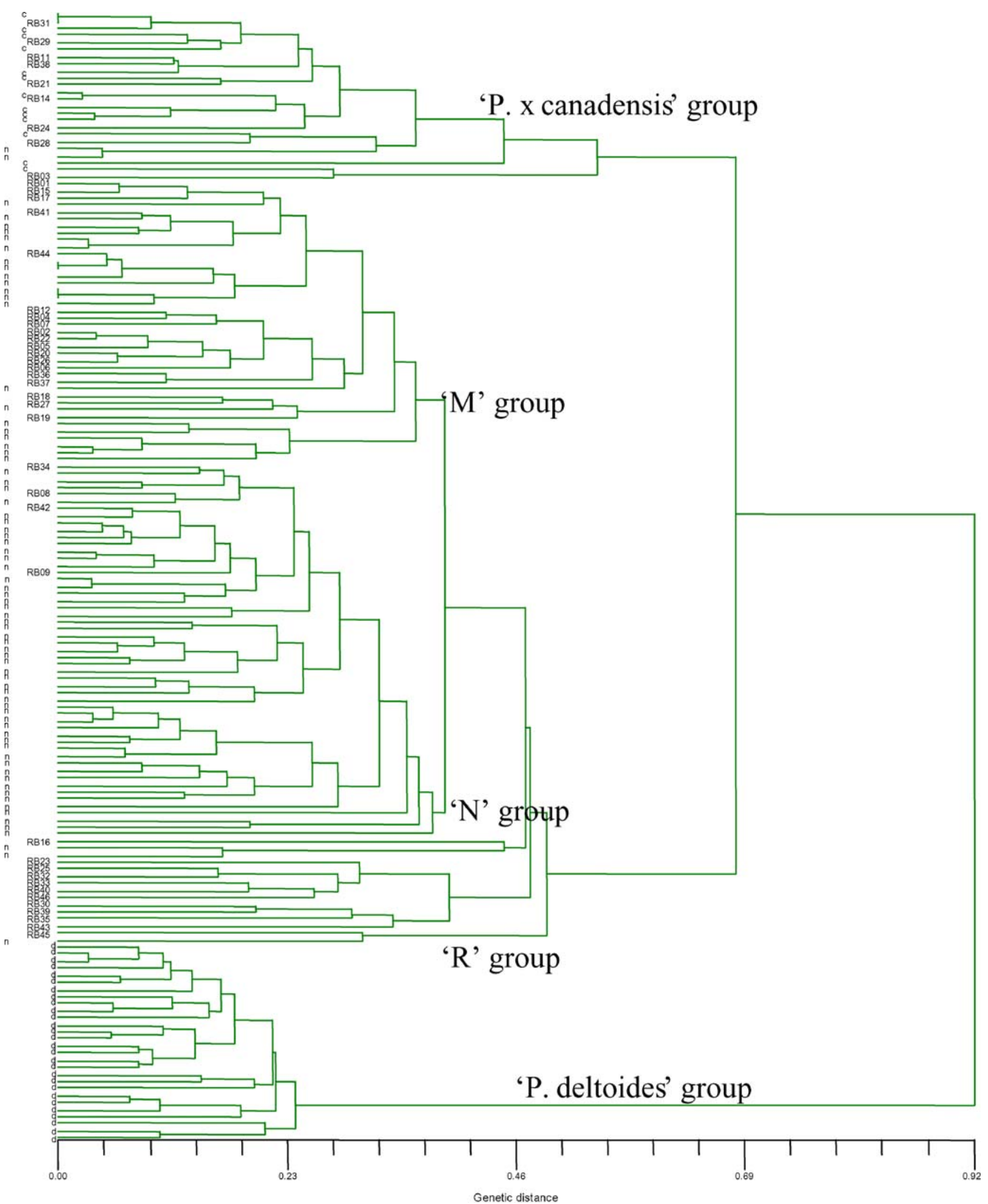

Fig. 2 UPGMA dendrogramme based on AFLP data. Next to the RB trees sampled for this study, the analysis included $P$. nigra $(n)$ trees are from the Gendt population ( $\mathrm{Z}$ in Fig. 1), P. deltoides $(d)$ trees are from the reference collection of INBO, and a number of $P$. $x$ canadensis cultivars $(c)$ 
cultivar I-214, for instance, was homozygous for the $P$. deltoides allele ' $\mathrm{g}$ ' at WPMS09.

The genotype of 24 of the RB trees was consistent with P. nigra (Table 2). Some others (such as RB40 and RB46) have one $P$. deltoides-specific allele at loci WPMS09 and WPMS18, which is consistent with a hybrid category (F1, F2 or various backcrosses). RB28, RB35 and RB38 contained P.-deltoides-specific alleles at loci WPMS09 or WPMS18 in homozygous state (RB38 even at both loci). They may be F2 hybrids or backcrosses to P. deltoides.

Overall, the trees originally placed in the P. nigra ' $\mathrm{N}$ ' cluster based on AFLP data were confirmed to be P. nigra, and the trees in the $P . x$ canadensis cluster indeed contained $P$. deltoides alleles. However, many RB trees from the other two $P$. nigra clusters contained some $P$. deltoides alleles as well. In these cases, neither AFLP clustering nor inspection of the microsatellite genotype at these seven loci could differentiate between F2 and various backcrosses.

Interestingly, the hybrid trees were not distributed randomly across the sampled sites but located mainly in locations C, F, G and P (Table 2). Possibly more hybrid clones have been planted near those locations, which have functioned as parents.

Hybrid analysis using Bayesian posterior probabilities with NewHybrids

The above analyses do not use all available genotype information. Clustering of AFLP data forces a decision on nodes in the tree based on most common patterns and may override intermediate or alternative positions. In addition, the existence of groups in a dendrogramme does not immediately indicate what common ancestry the members may have. When analysing microsatellite loci, the ancestry is based on the presence of a few diagnostic or informative alleles at only some of the loci, while information from allele frequency differences on other loci is ignored. For instance, the presence of diagnostic alleles at WPMS09 and WPMS18 in heterozygous state is consistent with an F1 but also with many other classes of hybrids (F2 and both types of backcrosses). Anderson and Thompson's (2002) programme NewHybrids enables calculating the posterior probability that a sample belongs to each of the parental and various hybrid classes (F1s, F2s and backcrosses with each parental species), based upon a genetic model, using all information in frequency differences between alleles, and incorporating the uncertainty due to sampling error in the allele frequencies.

NewHybrids analysis of the natural population near Gendt produced the highest probabilities $(>>0.9)$ to be $P$. nigra for all trees in the natural population near Gendt except two trees. These two trees were already under suspicion (Arens et al. 1998). The inferred probabilities for the commercial P. $x$ canadensis varieties were interesting, as two of them were classified as F2, not F1, with high probability ( $P=0.65$ for 'Gelrica', 0.91 for I-214). 'Heidemij' may be an $\mathrm{F} 2(P=0.36)$ or a $\mathrm{BC}$ to $P$. nigra $(P=0.49)$. These three clones have originally been selected from natural hybridisation events (Houtzagers 1937; http://www. populus.it/ipcipccloni.php). 'Blanc de Poitou' is most likely $(P=0.71)$ a $\mathrm{BC}$ to $P$. nigra. This indicates that they represent the progeny of more advanced crosses rather than being F1 hybrids. When we ran NewHybrids with the hybrid cultivars and only ten samples from each of the other groups (not shown), the exact probabilities changed somewhat but always concerned $\mathrm{F} 2$ and/or BC to P. nigra classes, indicating the stability of the assignments. All EUFORGEN Core Collection plants were clearly P. nigra (Fig. 3), except for KAE-N.90.013 from Turkey, which was $\mathrm{BC}$ to $P$. nigra $(P=0.54)$ or $\mathrm{F} 2(P=0.32)$.

When we included the RB trees sampled along the Rhine together with the P. nigra and P. deltoides trees, NewHybrids almost always assigned the RB trees clearly to one genotype class, often with probability $>0.8$. Using AFLP data, 24 of the $44 \mathrm{RB}$ samples (which is only slightly more than $50 \%$ ) were pure $P$. nigra, 13 were F1 hybrids, five were backcrosses to $P$. nigra, while two classified best in the category pure $P$. deltoides. Nearly all non- $P$. nigra $\mathrm{RB}$ trees are located in the ' $P$. $x$ canadensis' and ' $R$ ' groups in the AFLP-based dendrogramme, while both ' $\mathrm{M}$ ' and ' $\mathrm{N}$ ' groups are nearly completely pure $P$. nigra (Fig. 2).

For those RB plants for which also microsatellite data were available (listed in Table 2), the NewHybrids analysis of seven loci produced high posterior probabilities to classes $P$. nigra, F2 and $\mathrm{BC}$ to $P$. nigra (an example of the probability output is given in Fig. 3; all results included in Table 2). The high probability using microsatellite data was based on the allele frequencies at all seven loci because the two or three diagnostic loci were heterozygous in nearly all of these plants, on which basis one cannot distinguish between F1, F2 or BCs. In addition, the plants that were homozygous at locus WPMS09 for the P. deltoides allele 'g' were given high probability for being F2 not BC to $P$. deltoides. This is consistent with the presence of many more $P$. $x$ canadensis clones compared to pure $P$. deltoides trees.

Conspicuously absent was the class F1 because the plants that were labelled F1 based on the AFLP data were given high probabilities for $\mathrm{F} 2$ or $\mathrm{BC}$ to $P$. nigra classes based on the microsatellite data. This is not unexpected, as the $P . x$ canadensis trees themselves are already more advanced than F1. In this case, the AFLP result may have been affected by the fact that the NewHybrids programme 


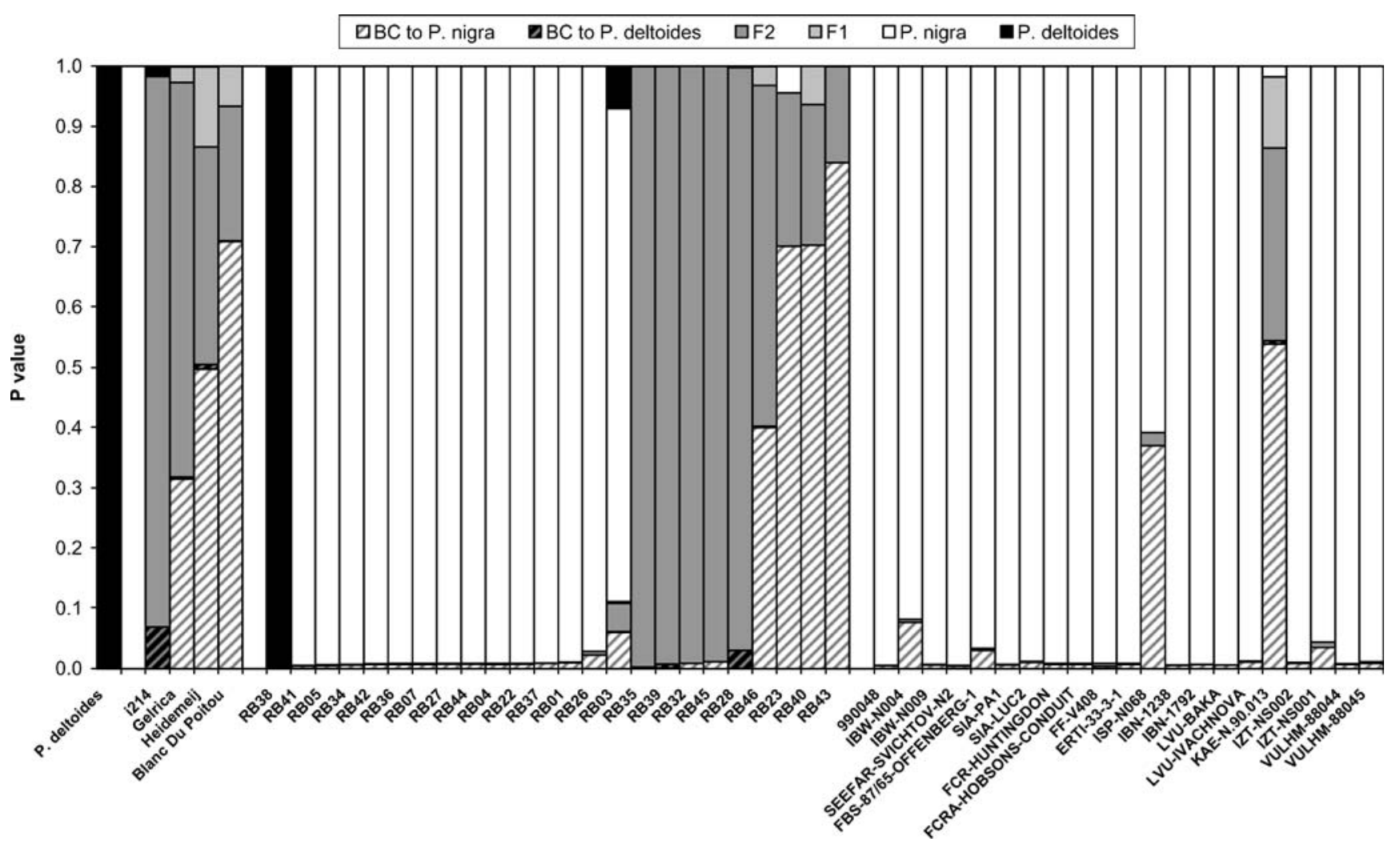

Fig. 3 Posterior probabilities of genotype frequency classes for microsatellite data of a subset of the samples

assumes that the (dominant) bands are homozygous. As could be expected, the class BC to P. deltoides was absent with both marker systems.

Correlation with morphology

For $21 \mathrm{RB}$ trees, we could compare detailed morphological data of very young leaves with the most likely genotype as classified by NewHybrids (Table 3). Six out of eight trees classified by NewHybrids as F1, F2 or BC to P. nigra did contain some P. $x$ canadensis morphological characteristics (leaf colour or pubescense of leaf margins). However, of 12 trees that were classified as P. nigra by NewHybrids only six had been identified as such based on morphology.

\section{Discussion}

Hybrid detection

AFLP and microsatellite markers were both able to distinguish $P$. deltoides from $P$. nigra and to detect the presence of hybrid trees. Of 48 AFLP polymorphic bands produced with one primer pair, only one was diagnostic between $P$. nigra and $P$. deltoides, but most bands frequencies were different, and as such they were informative to various degrees. Similarly, next to three diagnostic microsatellite loci (PMGC14, WPMS09 and WPMS18, as in Fossati et al. 2003), we could use the allele frequency differences at the other loci in the Bayesian probability

Table 3 Comparison of morphology and NewHybrids inferred genotype class

\begin{tabular}{|c|c|c|c|c|c|c|}
\hline \multirow{2}{*}{\multicolumn{2}{|c|}{$\begin{array}{l}\text { Groups based on morphological characteristics } \\
\text { Colour of young leaf hairs on leaf margin }\end{array}$}} & \multicolumn{5}{|c|}{ NewHybrids inferred genotype } \\
\hline & & \multirow{2}{*}{$\begin{array}{l}\text { P. nigra } \\
6\end{array}$} & \multirow{2}{*}{$\begin{array}{l}\mathrm{F} 2 \text { or } \mathrm{BC} \\
2\end{array}$} & \multirow{2}{*}{ F1 } & \multirow{2}{*}{$\begin{array}{l}\text { P. deltoides } \\
0\end{array}$} & \multirow{2}{*}{$\frac{\text { Total }}{8}$} \\
\hline Green & absent & & & & & \\
\hline (Red)brown & absent & 5 & 3 & 1 & 0 & 9 \\
\hline Green & pubescent & 0 & 1 & 0 & 0 & 1 \\
\hline (Red)brown & pubescent & 1 & 1 & 0 & 1 & 3 \\
\hline Total & & 12 & 7 & 1 & 1 & 21 \\
\hline
\end{tabular}


calculations using NewHybrids. For the P. $x$ canadensis hybrid cultivars, this clearly showed that they were a mixed group of variable parentage, with various probabilities for F2, BC to P. nigra and $\mathrm{BC}$ to $P$. deltoides classes. Heinze (1998) observed that all P. $x$ canadensis clones sampled in Austria had isozyme patterns that were consistent with F1 hybrids because they were heterozygous at the four to five loci tested. However, using that information, F2 and BC's are possible as well. It is known that several cultivated poplar clones are selected from half-sib open pollinated progeny resulting from natural hybridisation. The parental origin for these clones is not known. This is for example the case for the clones "Gelrica", "Heidemij" and "I-214". Our results show that hybrid cultivars from these programmes could represent, in genetic terms, second backcrosses (BC2) or crosses of F2 trees. This type of analysis can help to identify the genetic origin of cultivated clones.

\section{Hybrids in natural populations}

Amongst the young trees sampled, we found P. nigra trees, but nearly half of them classified as F2 between P. nigra and $P$. deltoides or $\mathrm{BC}$ to $P$. nigra. The latter trees could be the result of outcrossing of $P$. nigra as a mother with $P$. $x$ canadensis pollen donors, or vice versa. Siring by $P$. $x$ canadensis pollen is a real possibility for solitary $P$. nigra trees but not for those in large populations, as Vanden Broeck et al. (2003) found that the percentage of outcrossing of $P$. nigra with non- $P$. nigra trees was almost zero as long as $P$. nigra males were nearby. Therefore, it is also possible that young hybrid poplars are offspring of female $P$. $x$ canadensis trees, with $P$. $x$ canadensis or $P$. nigra cv Italica as a father. These two groups are by far the most common trees in the sampled area.

P. $x$ canadensis trees often do not produce seeds, but if they do these seeds can be germinated easily (R. Beringen, personal observation). Consistent with this notion is the observation that many poplar seedlings of hybrid morphology occur along the Meuse in regions in which there are no P. nigra populations, but many $P$. $x$ canadensis trees do occur in these region (Vanden Broeck et al. 2004; R. Beringen, personal observation).

Because we focused our sampling on plants that had established themselves spontaneously, most probably from seed, the identification of many F2 hybrids or backcrosses to $P$. nigra indicates that it is possible for seeds with hybrid origin to establish under more or less natural conditions. In addition, we detected one tree that was identical to a commercial hybrid clone, Blanc du Poitou. This is in itself not surprising because cuttings of poplars readily root and establish. Alternatively, the tree may have been planted. Two other trees classified best as 'pure' P. deltoides. P. deltoides cultivars are rare in The Netherlands compared to hybrid clones, but 'deltoides' alleles can also be derived from $P . x$ generosa hybrids, which are Populus trichocarpa $\times P$. deltoides $(=\mathrm{TxD})$. The female clones (commercial cultivars) of P. x generosa 'Beaupre', 'Boelare','Donk' and 'Raspalje' have been frequently planted in the Netherlands.

Former studies already indicated that cultivated poplars can produce viable seeds and seedlings in the field. Vanden Broeck et al. (2004) studied the genetic origin of young poplar seedlings that voluntary colonised the gravel banks of the river Meuse on the Dutch-Belgium border. Although they observed that cultivated poplars were reproductive along the Meuse river and produced seedlings that could survive the water dynamics over several years, they did not find pure black poplar seedlings along a stretch of the Meuse where only relict individuals of black poplar were present. In this study, we showed that seedlings of black poplar and hybrid poplars can be found on the same river banks and therefore may compete for the same habitat.

Fossati et al. (2003), using the same diagnostic microsatellite alleles, did identify some old trees in their Italian population as hybrids, but they concluded it was not introgression but human-mediated planting of cuttings of hybrid poplars. This was partly based on the fact that the same genotypes were present as more than one tree and that no trace of any of the $P$. deltoides alleles could be found in younger trees. In the UK, young natural populations of hybrid poplars were found on damp waste grounds. At one site, the parentage was inferred to be most likely $P$. $x$ canadensis "Marilandica" $\times$ P. $x$ canadensis "Serotina", as these were the only mature trees in the surrounding area (Stace 1997). Similarly, at another site, the parentage was determined to be probably Populus candicans Ait. (Balsam poplar) $\times$ P. nigra (Gilbert 1993). P. $x$ canadensis "Marilandica" is also believed to be the seed parent of P. $x$ canadensis "Gelrica", a cultivar originated in the Netherlands around c. 1865 (Houtzagers 1937).

Use of morphological characters

Because offspring of crosses between $P$. nigra and $P$. $x$ canadensis trees can be, in genetic terms, quite diverse types of backcross or crosses between hybrid plants beyond $\mathrm{F} 1$, one may expect that the morphological characteristics of such plants could be quite variable, as many morphological characteristics in plants are thought to be unlinked and based on few genes, as was observed in, e.g. wild apple hybrids (Larsen et al. 2006). The observations made on the RB trees (Table 3) are consistent with this hypothesis. In general, there was a correlation between morphological traits and the genetic status, as more than $80 \%$ of the genetically not pure $P$. nigra plants (F1, F2 or $\mathrm{BC}$ ) were morphologically also assigned as being non- $P$. nigra. However, also about $50 \%$ of the trees that were genetically 
identified as P. nigra with high probability had been under suspicion on account of morphology (e.g. RB3, which had red-brown young leaves). These trees might be F3 or further backcrosses. Young trees with a morphology such as RB3 are observed frequently along the Rhine river. The two-way misclassification may indicate that the morphological criteria are not very useful, as they do correctly identify $P . x$ canadensis and $P$. deltoides based on cilia (present) and young leaf colour (red-brown), but they cannot identify $P$. nigra trees as their morphology is variable. It may, however, also indicate that many intermediate genotypes exist alongside'pure' $P$. nigra trees. Progressive backcrosses of hybrids with $P$. nigra would produce trees with predominantly $P$. nigra traits but with variable presence of some hybrid-like traits.

\section{Consequences for nature management}

The results from this paper corroborate what botanists already suspected: that poplar trees found in natural and semi-natural habitats are mostly pure $P$. nigra, but some are offspring of hybrid clones (here category F2) or offspring of $P$. nigra sired with $P . x$ canadensis pollen (category $\mathrm{BC}$ to $P$. nigra). Currently, we do not know the exact parentage of such hybrids. When mother and seed genotypes are determined with microsatellite makers, the partial genotype of the father can be inferred. Tabbener and Cottrell (2003) performed such an analysis on trees of various Populus species in the Royal Botanical Garden in Edinburgh and Vanden Broeck et al. (2004) on offspring of a single P. nigra tree. In general, these studies showed that, given sufficient pollen of the own species, the black poplar females do not produce hybrid seeds. Only when the P. nigra mother plant is solitary and surrounded by many plants of hybrid origin or of other species does hybridisation takes place. Such situations do occur. The offspring of such crosses cannot be identified by cpDNA, as they contain P. nigra chloroplasts.

In view of the occurrence of hybridisation and establishment as observed in our study, in which hybrid trees are nearly as numerous as $P$. nigra trees, an efficient conservation method may be to enhance the number of pure $P$. nigra trees and populations by planting (Vanden Broeck et al. 2005). The number of $P$. nigra trees does not automatically increase in nature development projects, as the results of this study indicate that hybrid cultivated poplars may compete for, and subsequently occupy, the same ecological niche as native poplars.

An alternative view is to acknowledge that the establishment of hybrid and mixed origin offspring on natural locations that used to be exclusively for P. nigra is something that started with human activity (planting of hybrid poplars by man) but that now occurs spontaneously. The establishment of hybrid poplars may initially be non-adaptive or even maladaptive but may also lead to adaptive evolution through the production of hybrid genotypes that are more fit than their parents (Arnold 1997). This may also be important in the light of a changing climate. Progressive hybridisation, germination and selection will lead to a new type of poplar. In Germany, hybrid poplar is already being called a 'anökophyt' - a species that develops under human influence (Keil and Loos 2004). A second possibility is that the hybrids actually have an increased fitness, whose heterosis may be maintained by clonal propagation. Increased clonal propagation was found in Populus $x$ canescens, the natural hybrid of Populus alba and Populus tremula, in the Austrian Danube valley (Van Loo et al. 2008). Our dataset concerned seedlings, so we do not yet know how extensive they will propagate clonally. The large natural population of mature P. nigra trees near Gendt did show extensive clonal propagation, but these trees could clearly be classified as pure $P$. nigra.

In both scenarios, further research is needed to determine whether poplar hybrid seedlings have a competitive advantage over pure black poplar seedlings or vice versa, especially if river flow dynamics change as a result of increased weather variability due to climate change. Factors such as fertility, seed dispersal distance, seed and seedling establishment and vegetative reproduction have a strong effect on gene flow and merit further considerations. With regard to the occurrence of advanced backcrosses of $P$. $x$ canadensis (and $P . x$ generosa) clones to P. nigra an in-depth study is warranted. Such a study would have to start with a detailed analysis of the commercial clones planted across northwestern Europe during the last century, using a large number of markers spread evenly across the genome that have frequency differences between the parental species.

Acknowledgements This study has been carried out with financial support from the Netherlands' Ministry of Agriculture, Nature and Food Safety and from the Commission of the European Community, Network of Excellence "Evoltree", contract no. 016322, under the 6th Framework Programme, priority 6: Sustainable development, Global Change and Ecosystems. It does not necessarily reflect its views and in no way anticipates the Commission's future policy in this area. We thank Veronique Storme and Eric Anderson for useful suggestions.

Open Access This article is distributed under the terms of the Creative Commons Attribution Noncommercial License which permits any noncommercial use, distribution, and reproduction in any medium, provided the original author(s) and source are credited.

\section{References}

Anderson EC, Thompson EA (2002) A model-based method for identifying species hybrids using multilocus genetic data. Genetics 160:1217-1229

Arens P, Coops H, Jansen J, Vosman B (1998) Molecular genetic analysis of Black poplar (Populus nigra L.) along Dutch rivers. Mol Ecol 7:11-18 
Arnold ML (1997) Natural hybridization and evolution. Oxford University Press, Oxford

Benetka V, Mottl J, Vacková K, Pospíšková M, Dubský M (1999) Estimation of the introgression in the Populus nigra L. population by means of isozyme analysis. Silvae Genet 48:218-223

Beringen R (1998) Natuurlijke verjonging en hybridisatie bij populieren (Populus nigra en P. x canadensis). Gorteria 24:139-148

Boom BK (1982) Nederlandse dendrologie, 12e druk. Veenman, Wageningen

Booy G, Hendriks RJJ, Smulders MJM, Van Groenendael JM, Vosman B (2000) Genetic diversity and the survival of populations. Plant Biol 2:379-395

Buerkle CA (2005) Maximum-likelihood estimation of a hybrid index based on molecular markers. Mol Ecol Notes 5:684-687

Castiglione S, Wang G, Damiani G, Bandi C, Bisoffi S, Sala F (1993) RAPD fingerprints for identification and for taxonomic studies of elite poplar (Populus spp) clones. Theor Appl Genet 87:54-59

Cervera M-T, Storme V, Ivens B, Gusmão J, Liu BH, Hostyn V, Van Slycken J, Van Montagu M, Boerjan W (2001) Dense genetic linkage maps of three Populus species (Populus deltoides, $P$. nigra and $P$. trichocarpa) based on AFLP and microsatellite markers. Genetics 158:787-809

Epifanio JM, Phillipp DP (1997) Sources for misclassifying genealogical origins in mixed hybrid populations. J Hered 88:62-65

Fossati T, Grassi F, Sala F, Castiglione S (2003) Molecular analysis of natural populations of Populus nigra L. intermingled with cultivated hybrids. Mol Ecol 12:2033-2043

Frison E, Lefèvre F, de Vries S, Turok J (1995) Populus nigra network. Report of the first meeting, 3-5 October 1994, Izmit, Turkey. IPGRI, Rome

Gilbert OL (1993) Regenerating Balsam Poplar (Populus candicans Ait.) X Black Poplar (P. nigra L.) (Salicaceae) at a site in Leeds. Watsonia 19:188-190

Goudet J (1995) Fstat version 1.2: a computer program to calculate Fstatistics. J Hered 86:485-486

Heinze B (1997) A PCR marker for a Populus deltoides allele and its use in studying introgression with native European Populus nigra. Belg J Bot 129:123-130

Heinze B (1998) PCR-based chloroplast DNA assays for the identification of native Populus nigra and introduced poplar hybrids in Europe. For Gen 5:33-40

Heinze B, Lickl E (2002) Rare, but steady, introgression in Austrian black poplar as a long-term risk? In: van Dam B, Bordács S (eds) Genetic diversity in river populations of European black poplarimplications for riparian eco-system management. Proceedings of an International Symposium held in Szekszárd, Hungary from 16-20 May, 2001. Csiszár Nyomda, Budapest, pp 169-175

Holderegger R, Angelone S, Brodbeck S, Csencsics D, Gugerli F, Hoebee SE, Finkeldey R (2005) Application of genetic markers to the discrimination of European Black Poplar (Populus nigra) from American Black Poplar (P. deltoides) and Hybrid Poplars (P. $x$ canadensis) in Switzerland. Trees 19:743-748

Houtzagers G (1937) Het geslacht Populus in verband met zijn beteekenis voor de houtteelt. H. Veenman and Zonen, Wageningen

Hughes FMR, Adams WM, Muller E, Nilsson C, Richards KS, Barsoum N, Decamps H, Foussadier R, Girel J, Guilloy H, Hayes A, Johansson M, Lambs L, Pautou G, Peiry J-L, Perrow M, Vautier F, Winfield M (2001) The importance of different scale processes for the restoration of floodplain woodlands. Regul Rivers Res Manag 17:325-345

Janssen A (1997) Unterscheidung der beiden Schwarzpappelarten Populus nigra L und $P$. deltoides March sowie ihrer Arthybride P. $x$ euramericana (Dode) Guinier mit Hilfe von Isoenzymmustern. Die Holzzucht 51:17-23

Jones CJ, Edwards KJ, Castiglione S, Winfield MO, Sala F, Van de Wiel C, Bredemeijer G, Vosman B, Matthes M, Daly A,
Brettschneider R, Bettini P, Buiatti M, Maestri E, Malcevschi A, Marmiroli N, Aert R, Volckaert G, Rueda J, Linacero R, Vazquez A, Karp A (1997) Reproducibility testing of RAPD, AFLP and SSR markers in plants by a network of European laboratories. Mol Breeding 3:381-390

Keil P, Loos GH (2004) Ergasiophygophyten auf Industriebrachen des Ruhrgebietes. Flor Rundbr 38(1/2):101-112

Larsen AS, Asmussen CB, Coart E, Olrik DC, Kjær ED (2006) Hybridization and genetic variation in Danish populations of European crab apple (Malus sylvestris). Tree Genet Genomes 2:86-97

Lefèvre F, Legionnet A, de Vries S, Turok J (1998) Strategies for the conservation of a pioneer tree species, Populus nigra L., in Europe. Genet Sel Evol 30(Suppl. 1):S181-S196

Lefèvre F, Bordács S, Cottrell J, Gebhardt K, Smulders MJM, Vanden Broeck A, Vornam B, Van Dam BC (2002) Recommendations for riparian ecosystem management based on the general frame defined in EUFORGEN and results from EUROPOP. In: van Dam B, Bordács S (eds) Genetic diversity in river populations of European black poplar-implications for riparian eco-system management. Proceedings of an International Symposium held in Szekszárd, Hungary from 16-20 May, 2001. Csiszár Nyomda, Budapest, pp 157-161

Lexer, Buerkle CA, Joseph JA, Heinze B, Fay MF (2007) Admixture in European Populus hybrid zones makes feasible the mapping of loci that contribute to reproductive isolation and trait differences. Heredity 98:74-84

Odé B, Beringen R (2000) Floristisch Meetnet Oevers Zoete Rijkswateren 1999; uitwerking Rijntakken en evaluatie eerste ronde FLORON-rapport 20/RIZA nota nr. 2000.023. Leiden, The Netherlands

Pospíšková M, Šálková I (2006) Population structure and parentage analysis of black poplar along the Morava River. Can J For Res 36:1067-1076

Rajora OP (1989) Marker allozyme genes and alleles for differentiation of Populus deltoides, P. nigra, P. maximowiczii and their interspecific hybrids. Can J Bot 68:990-998

Rajora OP, Rahman MH (2003) Microsatellite DNA and RAPD fingerprinting, identification and genetic relationships of hybrid poplar (Populus $x$ canadensis) cultivars. Theor Appl Genet 106:470-477

Smulders MJM, Bredemeijer G, Rus-Kortekaas W, Arens P, Vosman B (1997) Use of short microsatellites from database sequences to generate polymorphisms among Lycopersicon esculentum cultivars and accessions of other Lycopersicon species. Theor Appl Genet 94:264-272

Smulders MJM, van der Schoot J, Arens P, Vosman B (2001) Trinucleotide repeat microsatellite markers for black poplar (Populus nigra L.). Mol Ecol Notes 1:188-190

Smulders MJM, Van der Schoot J, Ivens B, Storme V, Castiglione S, Grassi F, Fossati T, Bovenschen J, Van Dam BC, Vosman B (2002) Clonal propagation in black poplar (Populus nigra L.). In: van Dam B, Bordács S (eds) Genetic diversity in river populations of European black poplar-implications for riparian eco-system management. Proceedings of an International Symposium held in Szekszárd, Hungary from 16-20 May, 2001. Csiszár Nyomda, Budapest, pp 39-52

Smulders MJM, Cottrell JE, Lefèvre F, van der Schoot J, Arens P, Vosman B, Tabbener HE, Grassi F, Fossati T, Castiglione S, Krystufek V, Fluch S, Burg K, Vornam B, Pohl A, Gebhardt K, Alba N, Agúndez D, Maestro C, Notivol E, Volosyanchuk R, Pospíšková M, Bordács $\mathrm{S}$, Bovenschen $\mathrm{J}$, van Dam $\mathrm{BC}$, Koelewijn H-P, Halfmaerten D, Ivens B, van Slycken J, Vanden Broeck A, Storme V, Boerjan W (2008) Structure of the genetic diversity in Black poplar (Populus nigra L.) populations across European river systems: consequences for conservation and restoration. For Ecol Manag DOI: 10.1016/j.foreco.2007.10.063 
Stace C (1997) New flora of the British Isles, 2nd edn. Cambridge University Press, Cambridge

Storme V, Vanden Broeck A, Ivens B, Smulders MJM, Halfmaerten D, Van Slycken J, Boerjan W (2002) Ex-situ conservation of black poplar in Belgium, the margin of the geographical distribution area of the species. In: van Dam B, Bordács $\mathrm{S}$ (eds) Genetic diversity in river populations of European black poplar-implications for riparian eco-system management. Proceedings of an International Symposium held in Szekszárd, Hungary from 16-20 May, 2001. Csiszár Nyomda, Budapest, pp $61-72$

Storme V, Vanden Broeck A, Ivens B, Halfmaerten D, Van Slycken J, Castiglione S, Grassi F, Fossati T, Cottrell JE, Tabbener HE, Lefèvre F, Saintagne C, Fluch S, Krystufek V, Burg K, Bordács S, Gebhardt K, Vornam B, Pohl A, Alba N, Agúndez D, Bovenschen J, Van Dam BC, Van der Schoot J, Vosman B, Boerjan W, Smulders MJM (2004) Ex-situ conservation of black poplar in Europe: genetic diversity in nine gene bank collections and their value for nature development. Theor Appl Genet 108:969-981

Tabbener HE, Cottrell JE (2003) The use of PCR based DNA markers to study the paternity of poplar seedlings. For Ecol Manag 179:363-376

Turok J, Lefèvre F, De Vries S, Alba N, Heinze B, Van Slycken J (1998) Populus nigra network. Report of the fourth meeting 3-5 October 1997, Geraardsbergen, Belgium. IPGRI, Rome, 85 pp

Van der Schoot J, Pospíšková M, Vosman B, Smulders MJM (2000) Development and characterization of microsatellite markers in black poplar (Populus nigra L.). Theor Appl Genet 101:317-322

Van Loo M, Joseph JA, Heinze B, Fay MF, Lexer C (2008) Clonality and spatial genetic structure in Populus $x$ canescens and its sympatric backcross parent $P$. alba in a Central European hybrid zone. New Phytol 177:506-516
Van Raamsdonk LWD, Vrielink-van Ginkel M, Kik C (2000) Phylogeny reconstruction and hybrid analysis in Allium subgenus Rhizirideum. Theor Appl Genet 100:1000-1009

Van Slycken J (1996) Plant descriptors for Populus nigra. In: Turok J, Lefèvre F, Cagelli L, De Vries S (compilers) Populus nigra Network. Report of the second meeting. 10-12 September 1995. Casale Monferrato, Italy, pp 13-24

Vanden Broeck AH, Quataert P, Rodán-Ruiz I, Van Bockstaele E, Van Slycken J (2003) Pollen competition in P. nigra females revealed by microsatellite markers. For Gen 10:219-227

Vanden Broeck A, Storme V, Cottrell JE, Boerjan W, Van Bockstaele E, Quataert P, Van Slycken J (2004) Gene flow between cultivated poplars and native black poplar (Populus nigra L.): a case study along the river Meuse on the Dutch-Belgian border. For Ecol Manag 197:307-310

Vanden Broeck A, Villar M, Van Bockstaele E, Van Slycken J (2005) Natural hybridization between cultivated poplars and their wild relatives: evidence and consequences for native poplar populations. Ann For Sci 62:601-613

Vanden Broeck A, Cottrell J, Quataert P, Breyne P, Storme V, Boerjan W, Van Slycken J (2006) Paternity analysis of Populus nigra L. offspring in a Belgian plantation of native and exotic poplars. Ann For Sci 63:783-790

Vos P, Hogers R, Bleeker M, Reijans M, Van der Lee T, Hornes M, Frijters A, Pot J, Peleman J, Kuiper M, Zabeau M (1995) AFLP: a new technique for DNA fingerprinting. Nucleic Acids Res 23:4407-4414

Ziegenhagen B, Gneuss S, Rathmacher G, Leyer I, Bialozyt R, Heinze B, Liepelt S (2008) A fast and simple genetic survey reveals the spread of poplar hybrids at a natural Elbe river site. Conserv Genet DOI 10.1007/s10592-007-9349-4 